Article

\title{
Fragility Assessment of Geotechnical Seismic Isolated (GSI) Configurations
}

\author{
Davide Forcellini
}

check for

updates

Citation: Forcellini, D. Fragility Assessment of Geotechnical Seismic Isolated (GSI) Configurations. Energies 2021, 14, 5088. https:// doi.org/10.3390/en14165088

Academic Editors: Gye-Chun Cho and Ilhan Chang

Received: 24 July 2021

Accepted: 17 August 2021

Published: 18 August 2021

Publisher's Note: MDPI stays neutral with regard to jurisdictional claims in published maps and institutional affiliations.

Copyright: (C) 2021 by the author. Licensee MDPI, Basel, Switzerland. This article is an open access article distributed under the terms and conditions of the Creative Commons Attribution (CC BY) license (https:// creativecommons.org/licenses/by/ $4.0 /)$.
Department of Civil Engineering, Università di San Marino, Via Consiglio dei Sessanta, 47899 San Marino, San Marino; davide.forcellini@unirsm.sm

\begin{abstract}
Geotechnical seismic isolation (GSI) consists of an innovative technique to mitigate the effects of earthquakes based on interposing a superficial soil layer to filter the seismic energy from the soil to the structure. This approach is particularly applied in developing countries due to low-cost applications. In order to account the uncertainties, the presented paper aimed to develop fragility curves of 3D configurations performed by numerical finite element models. The mail goal is to assess and discuss the potentialities of GSI as a mitigation technique for several configurations. Opensees PL has been applied to perform the numerical analyses and to realistically reproduce the behaviour of GSI.
\end{abstract}

Keywords: GSI; analytical fragility curves; configurations; numerical simulations; OpenSeesPL

\section{Introduction}

Geotechnical Seismic Isolation (GSI) consists of a novel technique that applies different materials to reduce costs (installation and maintenance of the devices) connected with traditional base isolation. In this regard, many materials have been proposed, such as rubber-soil mixtures (RSM), geofoam, geomembranes/geotextiles, rocking isolation and natural stone pebbles, and kart tyres, as shown in [1]. In particular, extensive research was conducted on polyurethane, injectable in the soil below structures (new and existing ones), as shown in [2-4]. Other researchers proposed the use of sand and sand-bitumen mixtures [5-7] as GSI isolation materials.

On one side, GSI is conceivably an environmentally friendly and low-cost technology particularly valid for developing countries. On the other side, due to the level of its novelty, GSI applications required many experiments to prove their reliability. In this regard, experimental tests were conducted on shaking tables [8,9]. Tsiavos et al. [10] performed direct shear tests and small-scale $1 \mathrm{~g}$ shaking table tests. Tsang et al. [11] conducted centrifuge tests, while Kaneko et al. [12] proposed hybrid simulations. Another typology of verifications consists of numerical simulations, such as in [13-17]. In particular, the authors of [13] investigated the application of granulated rubber-soil mixtures to the seismic isolation for low-to-medium-rise buildings. Nonlinear models were proposed in [14] to study seismic isolation systems made of recycled tire-rubber. The application of GSI on bridges configurations was also proposed, [18].

It was recently demonstrated [1] that GSI effectiveness depends on the dynamic characteristics of the input motion in relation to the properties of the structure (mainly the fundamental periods). In order to extend the previous outcomes with numerical simulations, the present paper assesses GSI with a probabilistic-based approach based on developing analytical fragility curves in order to consider all the uncertainties connected with the definition of input motions. In particular, this paper aims to extend the previous contributions by considering several structural configurations with different parameters (in terms of stiffness and mass) to consider the effectiveness of GSI for realistic buildings. Therefore, it is possible to consider the following novelties: 
1. Simulating different structural configurations with different location of the liner ( $0.5 \mathrm{~m}, 10 \mathrm{~m}, 20 \mathrm{~m}$ and $30 \mathrm{~m}$ depth) to aid better insight into the role of GSI on different buildings.

2. Proposing parametric studies on several structural parameters (mass, stiffness) in order to relate the efficiency of GSI with the structural behaviours.

3. Development of analytical fragility curves that may consider the uncertainties with a probabilistic-based approach.

The paper is organized into six sections. In Section 2, the numerical models are presented and discussed. Section 3 clarifies the choice of the earthquakes applied in the study, while Section 4 shows the characteristics of the soils. Results are shown and discussed in Section 5, followed by the conclusions.

\section{Numerical Model}

Numerical simulations were performed with OpenSeesPL (an open-source computational platform) [18], by the Pacific Earthquake Engineering Research (PEER) centre. In particular, the Opensees PL platform, developed by the authors of [19] at University of California, San Diego, was applied to model the different case studies. Tridimensional soil meshes were described with BrickUP isoparametric elements. These elements allow to consider both the displacements (longitudinal, transversal and vertical: degree of freedom: 1,2 and 3, respectively) to simulate the dynamic response of the soil. One 3D mesh for every considered configuration (total: 4 , as shown in Figure 1) has been implemented to model a building resting on a sandy soil domain. What changes between the $43 \mathrm{D}$ meshes is the location of GSI that is located between the first (yellow) layer and the second (green) layer that have the same the same properties. The dimensions of the elements inside the mesh followed the previous contributions [1,17]. Furthermore, the performance of the lateral boundaries was verified by comparing the accelerations at the top of the mesh with those obtained under the free field (FF) conditions to reproduce wave mechanisms. Mesh discretization was derived considering a $100 \mathrm{~m} / \mathrm{s}$ as the lowest shear wave velocity and a $10 \mathrm{~Hz}$ as the maximum frequency.

Soil structure interaction has the main contribution in defining the effects of the soil on the structure and was herein modelled with several assumptions: (1) Particular attention has been paid to the boundary conditions, where absorbing boundaries have been applied at the base to dissipate the radiating waves. (2) The base nodes have been set free to move along the longitudinal and transversal directions to model the elastic half-space below the mesh, while vertical direction was fixed. (3) The lateral nodes have been constrained to simulate pure shear by applying period boundaries and to ensure free field conditions (that are not disturbed by the presence of the structure). At the lateral nodes, a penalty method (tolerance $=10^{-4}$ ) has been adopted to avoid problems with equations system conditions [18]. (4) The connections between the shallow foundations and the soil were built up as equal and can impose the displacements to be the same between the structure and the soil nodes and thus to capture the rocking component of the SSI. (5) The soil deposit was simulated using the multi-surface plasticity constitutive model [19]. Note that the presence of shallow foundations allows to consider kinematic interaction as the main source of SSI between the soil and the structure, as demonstrated in [20,21].

The benchmark reinforced concrete structure (Figure 2) was calibrated to be representative of residential low-rise building, performing the structure considered in [1] and called $\mathrm{S} 1$, with three floors ( $3.4 \mathrm{~m}$ each). Four columns in longitudinal direction ( $6 \mathrm{~m}$ spaced) and 2 in transversal direction ( $5 \mathrm{~m}$ spaced). The columns and the beams have been modelled with elastic beam column elements using the properties shown in Table 1. 

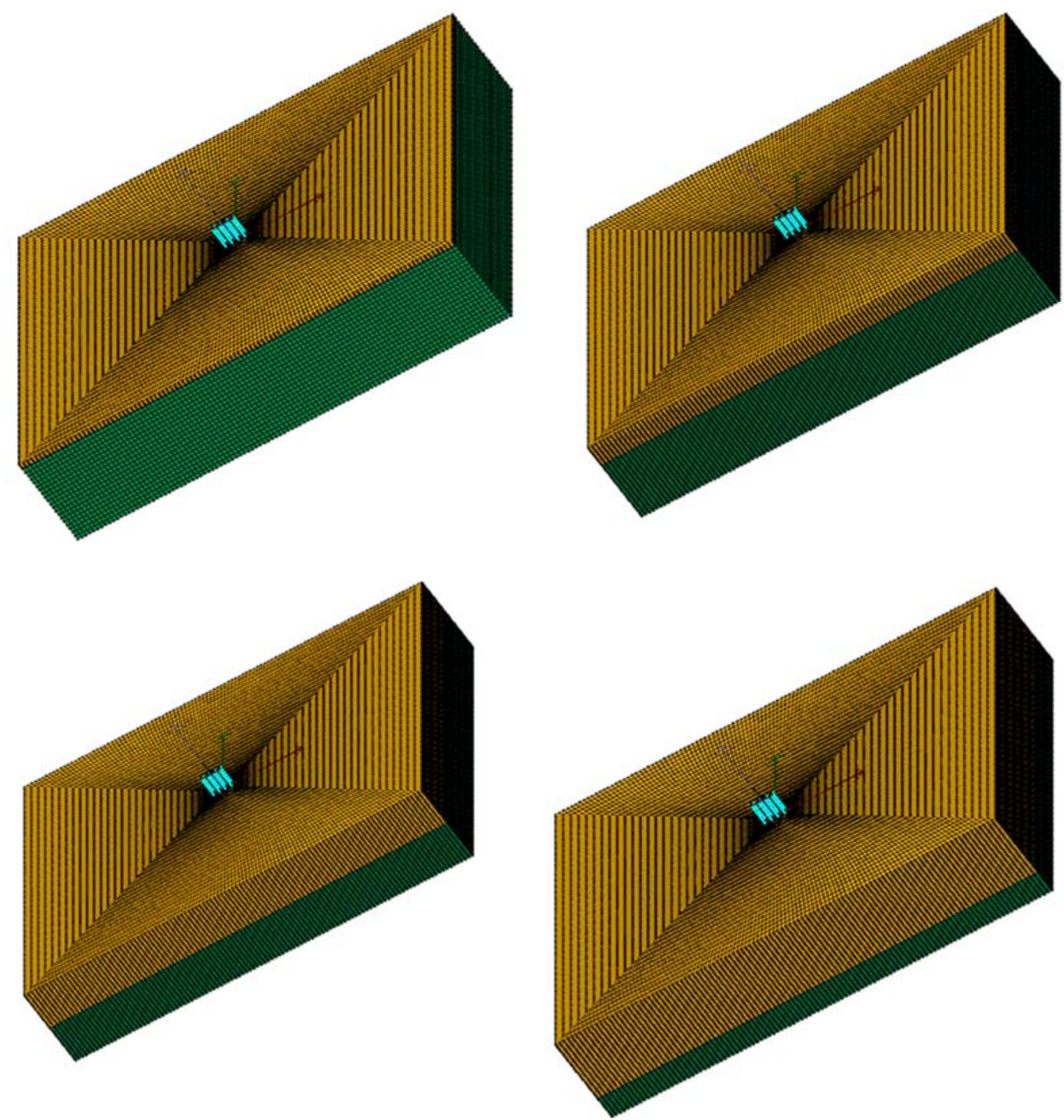

Figure 1. 3D models: they differ for the different positions of the liner: at foundation level (GSI1), at $10 \mathrm{~m}$ depth (GSI2), $20 \mathrm{~m}$ depth (GSI3) and $30 \mathrm{~m}$ depth (GSI4).

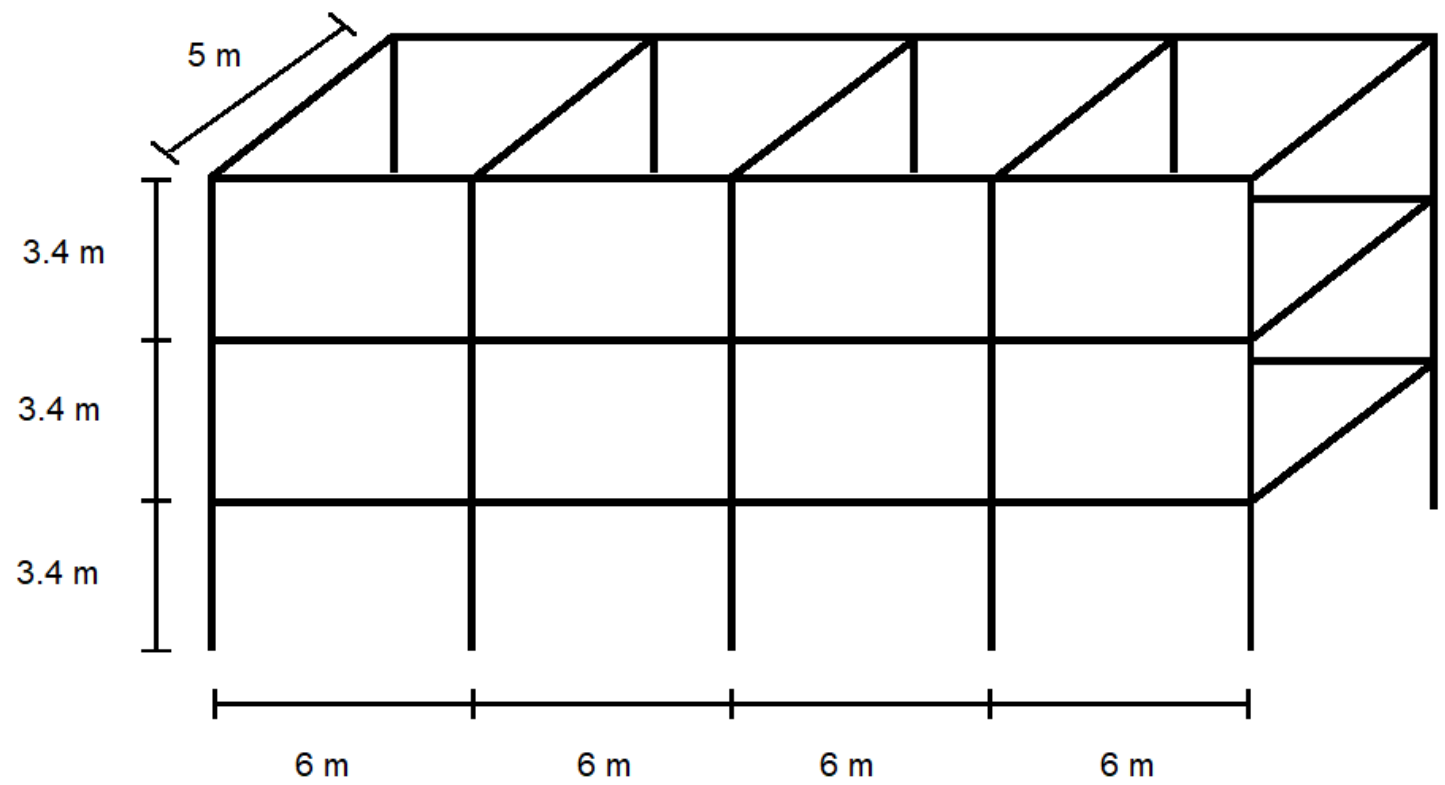

Figure 2. Benchmark RC structure. 
Table 1. Characteristics of the elastic beam columns.

\begin{tabular}{cc}
\hline Parameter & Value \\
\hline Mass density $\left(\mathrm{kN} / \mathrm{m}^{3}\right)$ & 24.0 \\
Young modulus $(\mathrm{kPa})$ & $3.50 \times 10^{7}$ \\
Shear modulus $(\mathrm{kPa})$ & $1.73 \times 10^{7}$ \\
Cross area $\left(\mathrm{m}^{2}\right)$ & 0.12 \\
Inertial moment $\left(\mathrm{m}^{4}\right)$ & $9.0 \times 10^{-4}$ \\
\hline
\end{tabular}

Shallow foundation was considered (slab dimensions: $28.4 \mathrm{~m} \times 34.4 \mathrm{~m}$, thickness: $0.5 \mathrm{~m}$ ) and a rigid concrete slab was modelled by applying equal degree of freedom to connect the nodes at the base of the columns with those of the soil domain. In order to simulate the interface between the columns and the slab, horizontal rigid links were defined, following the works in $[1,17]$. The foundation slab has been modelled elastically with an equivalent material that simulates the concrete and implementing the pressure independent multi-yield model (PIMY) [19], with the properties as shown in Table 2. The design of the foundation consisted in assessing the eccentricity for the most severe condition: minimum vertical loads (gravity and seismic loads) and maximum bending moments.

Table 2. Characteristics of the foundation.

\begin{tabular}{cc}
\hline Parameter & Value \\
\hline Mass density $\left(\mathrm{kN} / \mathrm{m}^{3}\right)$ & 24.0 \\
Shear modulus $(\mathrm{kPa})$ & $1.25 \times 10^{7}$ \\
Bulk modulus $(\mathrm{kPa})$ & $1.67 \times 10^{7}$ \\
\hline
\end{tabular}

Both GSI and the soil were modelled with a nonlinear hysteretic material named Pressure-Independent Multiyield [19] that applies a Von Mises multi-surface kinematic plasticity approach and an associate flow rule to capture both monotonic and hysteretic elasto-plastic response of both the soil and GSI. According to this formulation, plasticity is exhibited only in the deviatoric stress-strain response, while volumetric response is linear-elastic. Several GSI configurations were considered, by following the contributions proposed by [15] GSI1, GSI2, GSI3 and GSI4, with different position of the liner: at foundation level, at $10 \mathrm{~m}, 20 \mathrm{~m}$ and $30 \mathrm{~m}$ depth, respectively. Table 3 shows the number of elements and nodes used for the 3D numerical model. GSI was modelled in order to represent realistically a thin layer of deformable material, following the calibration proposed in [15], whose parameters are shown in Table 4. Some of these parameters (such as the density, Poisson's ratio) have little effect on the performance of GSI and were widely investigated by the authors of [13]. The soil was considered stiff, as it was demonstrated in [15] that the effectiveness of GSI depends on soil deformability. In particular, such conditions represent the case of a hard soil or a ground that has been strengthened with several techniques, such as densification. The parameters of the soil have been adopted from the one called Soil A in [15] and shown in Table 4.

Table 3. Characteristics of the 3D finite element models.

\begin{tabular}{ccc}
\hline Model & Number of Elements & Number of Nodes \\
\hline GSI1 & 298,000 & 311,200 \\
GSI2 & 353,600 & 387,950 \\
GSI3 & 354,200 & 388,120 \\
GSI4 & 353,600 & 387,950 \\
\hline
\end{tabular}


Table 4. Characteristic of the soil and GSI liner.

\begin{tabular}{ccc}
\hline Parameter & GSI & Soil \\
\hline Mass density $\left(\mathrm{kN} / \mathrm{m}^{3}\right)$ & 12.0 & 22.0 \\
Shear modulus $(\mathrm{kPa})$ & 120 & $5.60 \times 10^{7}$ \\
Bulk modulus $(\mathrm{kPa})$ & 390 & $7.50 \times 10^{7}$ \\
Shear wave velocity $(\mathrm{m} / \mathrm{s})$ & 10 & 1600 \\
Cohesion $[\mathrm{kPa}]$ & 40 & 10,000 \\
\hline
\end{tabular}

\section{Nonlinear Analyses}

Seventy earthquake records from the PEER NGA database (http: / / peer.berkeley.edu / nga/, accessed on 18 August 2021) were employed in the analyses to study the effect of the earthquake intensity on the response of the buildings. They were chosen in order to represent several intensities and reproduce soil deformations (and thus soil structure interaction) for several historical earthquakes. In particular, Table 5 presents the name, station, duration and peak ground acceleration (PGA) for each record.

Table 5. Characteristics of the foundation.

\begin{tabular}{|c|c|c|c|c|}
\hline Number & Earthquake & Station & Duration (s) & PGA (g) \\
\hline 1 & A-ELC & 1968 Borrego Mountain & 40.00 & 0.13 \\
\hline 2 & $\mathrm{~A} 2 \mathrm{E}$ & 1989 Loma Prieta & 39.96 & 0.18 \\
\hline 3 & FMS & 1989 Loma Prieta & 39.76 & 0.20 \\
\hline 4 & HVR & 1989 Loma Prieta & 39.96 & 0.14 \\
\hline 5 & SJW & 1989 Loma Prieta & 39.96 & 0.12 \\
\hline 6 & BAD & 1994 Northridge & 35.00 & 0.10 \\
\hline 7 & CAS & 1994 Northridge & 39.80 & 0.15 \\
\hline 8 & DWN & 1994 Northridge & 35.36 & 0.24 \\
\hline 9 & JAB & 1994 Northridge & 35.00 & 0.10 \\
\hline 10 & L01 & 1994 Northridge & 32.00 & 0.09 \\
\hline 11 & LOA & 1994 Northridge & 40.00 & 0.15 \\
\hline 12 & LV2 & 1994 Northridge & 32.00 & 0.10 \\
\hline 13 & PHP & 1994 Northridge & 60.00 & 0.08 \\
\hline 14 & PIC & 1994 Northridge & 40.00 & 0.19 \\
\hline 15 & SOR & 1994 Northridge & 36.48 & 0.07 \\
\hline 16 & VER & 1994 Northridge & 30.00 & 0.16 \\
\hline 17 & AGW & 1989 Loma Prieta & 40.00 & 0.18 \\
\hline 18 & CAP & 1989 Loma Prieta & 39.96 & 0.51 \\
\hline 19 & G03 & 1989 Loma Prieta & 39.96 & 0.55 \\
\hline 20 & G04 & 1989 Loma Prieta & 39.96 & 0.41 \\
\hline 21 & $\mathrm{HCH}$ & 1989 Loma Prieta & 39.10 & 0.24 \\
\hline 22 & CNP & 1994 Northridge & 25.00 & 0.43 \\
\hline 23 & FLE & 1994 Northridge & 30.00 & 0.28 \\
\hline 24 & LOS & 1994 Northridge & 20.00 & 0.54 \\
\hline 25 & PEL & 1994 Northridge & 40.00 & 0.23 \\
\hline 26 & RO3 & 1994 Northridge & 30.28 & 0.45 \\
\hline 27 & H-BCR & 1979 Imperial Valley & 37.62 & 0.59 \\
\hline 28 & $\mathrm{H}-\mathrm{CXO}$ & 1979 Imperial Valley & 37.82 & 0.28 \\
\hline 29 & H-E05 & 1979 Imperial Valley & 39.30 & 0.50 \\
\hline 30 & H-SHP & 1979 Imperial Valley & 15.72 & 0.46 \\
\hline 31 & G02 & 1989 Loma Prieta & 39.96 & 0.41 \\
\hline 32 & GOF & 1989 Loma Prieta & 39.96 & 0.30 \\
\hline 33 & Z-HVR & 1984 Morgan Hill & 39.98 & 0.31 \\
\hline 34 & O637 & 1994 Northridge & 47.78 & 0.75 \\
\hline 35 & JEN & 1994 Northridge & 28.62 & 0.57 \\
\hline
\end{tabular}


Table 5. Cont.

\begin{tabular}{|c|c|c|c|c|}
\hline Number & Earthquake & Station & Duration (s) & PGA (g) \\
\hline 36 & NWH & 1994 Northridge & 40.00 & 0.58 \\
\hline 37 & RRS & 1994 Northridge & 19.92 & 0.82 \\
\hline 38 & SCS & 1994 Northridge & 40.00 & 0.61 \\
\hline 39 & SYL & 1994 Northridge & 40.00 & 0.60 \\
\hline 40 & $\mathrm{C} 08$ & 1966 Parkfield & 26.12 & 0.23 \\
\hline 41 & A-JAB & 1987 Whittier Narrows & 34.30 & 0.22 \\
\hline 42 & A-SOR & 1987 Whittier Narrows & 28.72 & 0.14 \\
\hline 43 & B-ELC & 1968 Borrego Mountain & 40.00 & 0.07 \\
\hline 44 & $\mathrm{H}-\mathrm{C} 05$ & 1983 Coalinga & 40.00 & 0.16 \\
\hline 45 & $\mathrm{H}-\mathrm{C} 08$ & 1983 Coalinga & 32.00 & 0.10 \\
\hline 46 & H-NIL & 1979 Imperial Valley & 40.00 & 0.11 \\
\hline 47 & H-PLS & 1979 Imperial Valley & 18.76 & 0.06 \\
\hline 48 & $\mathrm{H}-\mathrm{VCT}$ & 1979 Imperial Valley & 40.00 & 0.12 \\
\hline 49 & A-STP & 1984 Morgan Hill & 28.00 & 0.05 \\
\hline 50 & Z-CAP & 1984 Morgan Hill & 36.00 & 0.14 \\
\hline 51 & $\mathrm{Z}-\mathrm{HCH}$ & 1984 Morgan Hill & 28.34 & 0.07 \\
\hline 52 & H06 & 1986 North Palm Springs & 40.00 & 0.07 \\
\hline 53 & INO & 1986 North Palm Springs & 30.00 & 0.12 \\
\hline 54 & A-CTS & 1987 Whittier Narrows & 39.96 & 0.06 \\
\hline 55 & A-HAR & 1987 Whittier Narrows & 40.00 & 0.07 \\
\hline 56 & A-SSE & 1987 Whittier Narrows & 22.94 & 0.05 \\
\hline 57 & A-STC & 1987 Whittier Narrows & 40.00 & 0.18 \\
\hline 58 & H-CAL & 1979 Imperial Valley & 39.54 & 0.14 \\
\hline 59 & $\mathrm{H}-\mathrm{CHI}$ & 1979 Imperial Valley & 40.00 & 0.29 \\
\hline 60 & A-KOD & 1980 Livermore & 20.98 & 0.16 \\
\hline 61 & A-SRM & 1980 Livermore & 40.00 & 0.06 \\
\hline 62 & Z-AGW & 1984 Morgan Hill & 29.98 & 0.04 \\
\hline 63 & W-G02 & 1984 Morgan Hill & 29.98 & 0.15 \\
\hline 64 & PHN & 1935 Port Hueneme & 28.42 & 0.11 \\
\hline 65 & NIL & 1966 Westmore & 40.00 & 0.10 \\
\hline 66 & A-CAS & 1987 Whittier Narrows & 21.18 & 0.38 \\
\hline 67 & A-CAT & 1987 Whittier Narrows & 32.92 & 0.06 \\
\hline 68 & A-DWN & 1987 Whittier Narrows & 40.00 & 0.24 \\
\hline 69 & A-W70 & 1987 Whittier Narrows & 31.94 & 0.20 \\
\hline 70 & A-WAT & 1987 Whittier Narrows & 29.70 & 0.10 \\
\hline
\end{tabular}

The nonlinear dynamic analyses were performed by following the approach adopted in $[20,21]$ which consists of running three steps (stages): In the first step, the soil initial stresses were calculated considering linear properties (weight, shear and bulk modulus). In step 2, the structure and the associated loads were applied, and the properties of the soil were changed from elastic to plastic. Twenty-five load steps were necessary in order to maintain the convergency requirements. Finally, Step 4 consisted of applying the input motion at the base of the soil mesh as acceleration time history. NewtonLineSearch algorithm was used in the analyses of Step 4.

\section{Fragility Curves}

This paper develops analytical fragility curves on the bases of the analyses that were performed with the 4 configurations and 70 input motions (total: 280 analyses). Fragility curves were proposed in the past decades for RC buildings (as shown in [21]) as graphical representations of the between the probability of exceeding selected damage states (DS) for levels of engineering demand parameters (EDP). They are useful for the assessments of damages at different levels of Intensity Measures (IM). In this paper, several assumptions were considered: (1) PGA is considered as the reference Intensity measure, (2) inter-story drift was considered as the reference EDP, (3) four states (slight, moderate, extensive and complete) were defined for interstory drifts $0.33 \%, 0.58 \%, 1.56 \%$ and $4 \%$, respectively, as proposed in [22]. In addition, (4) all uncertainties are represented by 
lognormal distributions. This allows to consider two representative parameters: the lognormal standard deviation $(\beta)$ and the mean $(\mu)$ of the lognormal seismic intensity measure, as detailed in [21].

Therefore, the results from the performed nonlinear analyses were used to build linear regressions and define the median and log-standard deviation values. The probability of exceedance for a specific PGA value was then calculated as

$$
\mathrm{P}[\mathrm{D} \geq \mathrm{Ci} \mid \mathrm{PGA}]=\Phi\left(\frac{\ln (\mathrm{PGA})-\mu}{\beta}\right)
$$

where,

$P$ is the probability of the structural damage (D) exceeding the i-th damage state (C); $\Phi$ is the standard normal cumulative distribution function;

PGA (Peak Ground Acceleration) is the selected intensity measure value;

$\beta$ is the lognormal standard deviation and

$\mu$ is the mean value of the lognormal seismic intensity measure (PGA).

\section{Results}

Following the previous contribution [1] where the capacity of the GSI was compared with the convectional foundation without considering any isolation approach, this section investigates the effects of several the location of the liner by comparing the four selected configurations. In particular, Figure 3 shows the results in terms of column drift (at the top of the structure) and PGA for GSI1, GSI2, GSI3 and GSI4. $\mathrm{R}^{2}$ was chosen to evaluate the correlations between the results (PGA Vs maximum interstory drifts) and thus demonstrating a good correlation for all the configurations (Table 6).

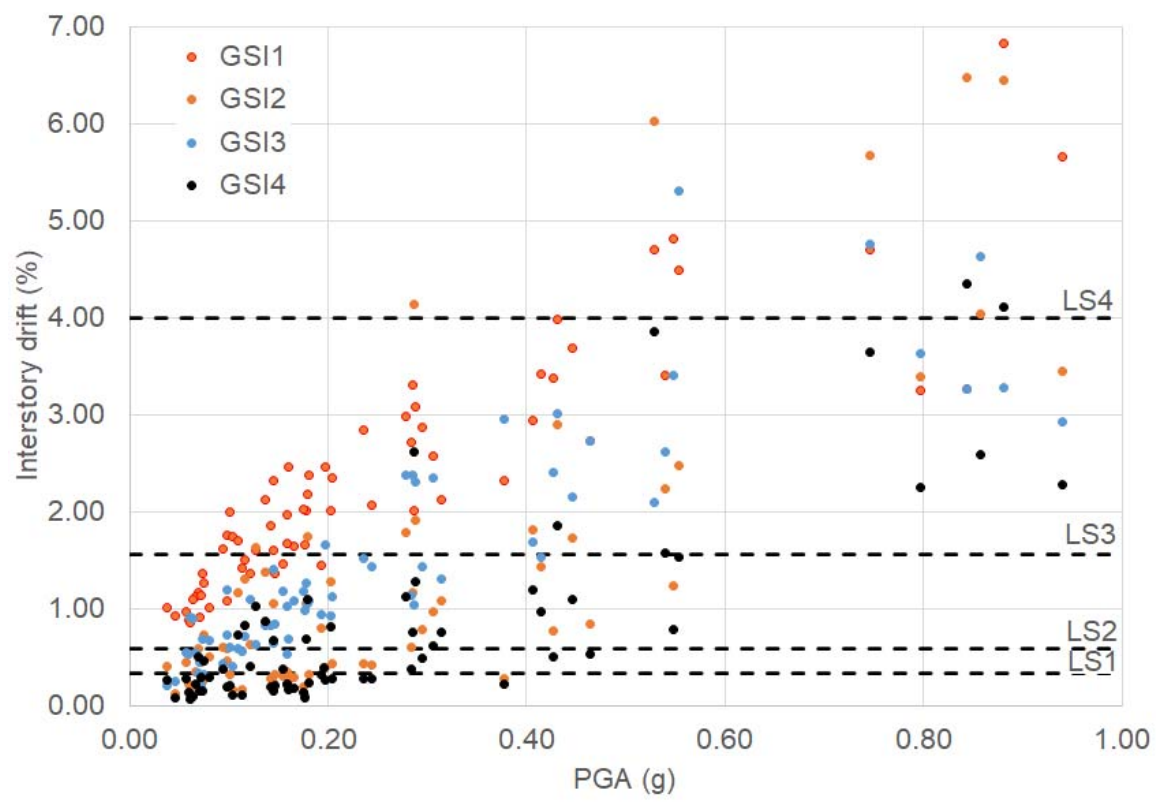

Figure 3. PGA vs. interstory drifts for GSI1, GSI2, GSI3 and GSI4.

Table 6. Characteristic of the soil and GSI liner.

\begin{tabular}{cc}
\hline Configuration & $\mathbf{R}^{\mathbf{2}}$ \\
\hline GSI1 & 0.835 \\
GSI2 & 0.845 \\
GSI3 & 0.838 \\
GSI4 & 0.825 \\
\hline
\end{tabular}


The linearization procedures allowed to calculate the values of the mean and the standard deviation for all the considered cases and developing analytical fragility curves, shown in Figures 4-7 for the selected limit states (LS1, LS2, LS3 and LS4) that display the relationship between PGA (g) and the probability of exceedance (PE). Note that for GSI1 (Figure 4), the level of damage is high and thus LS1 (slight damage) is not reached, demonstrating that the superficial location if GSI (configuration GSI1) does not help in reducing the damage to the structure and thus should be avoided. Figures 5-7 show that all the damage limits are reached, demonstrating that the most detrimental configuration is GSI1, when the liner is superficial [1].

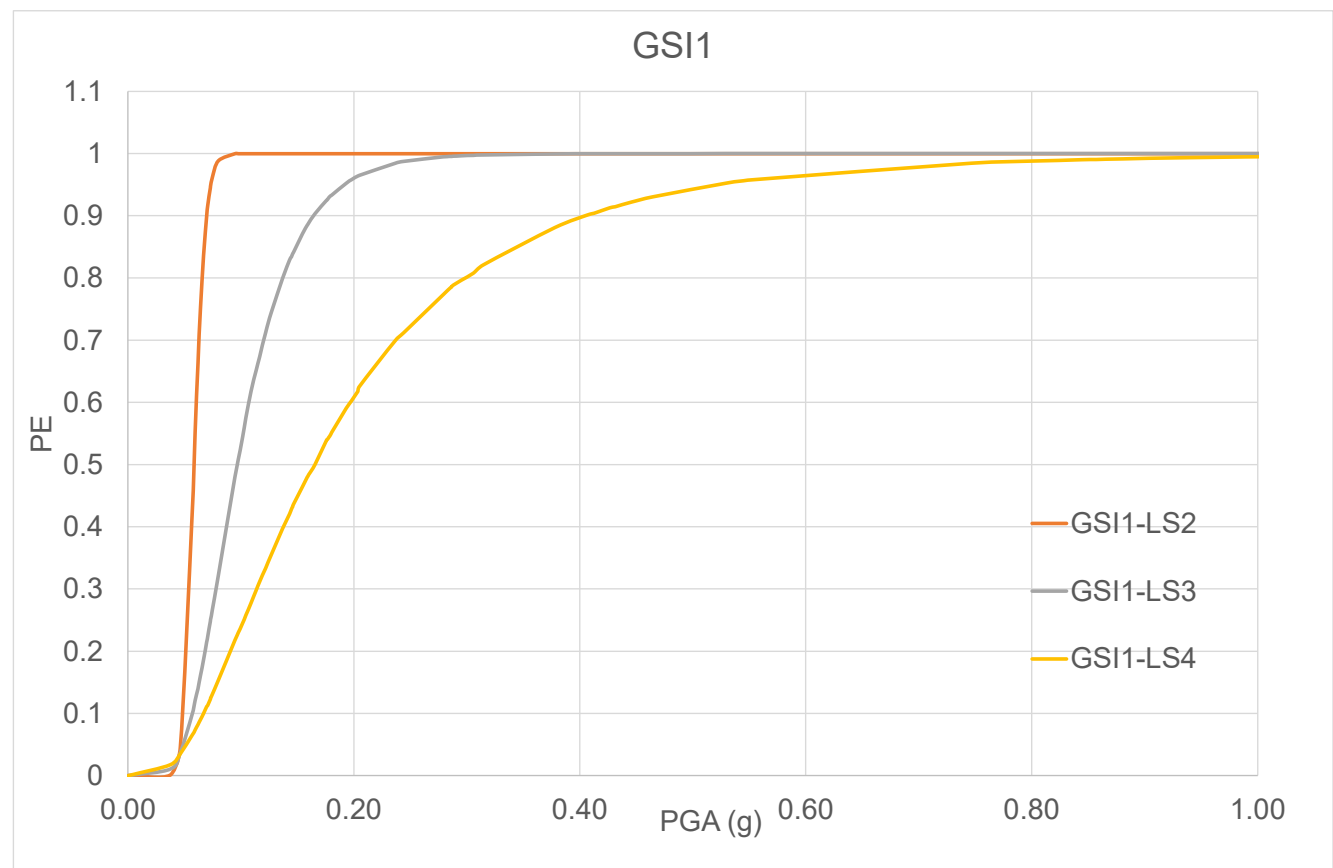

Figure 4. Fragility curve for GSI1: PGA vs. Probability of Exceedance (PE).

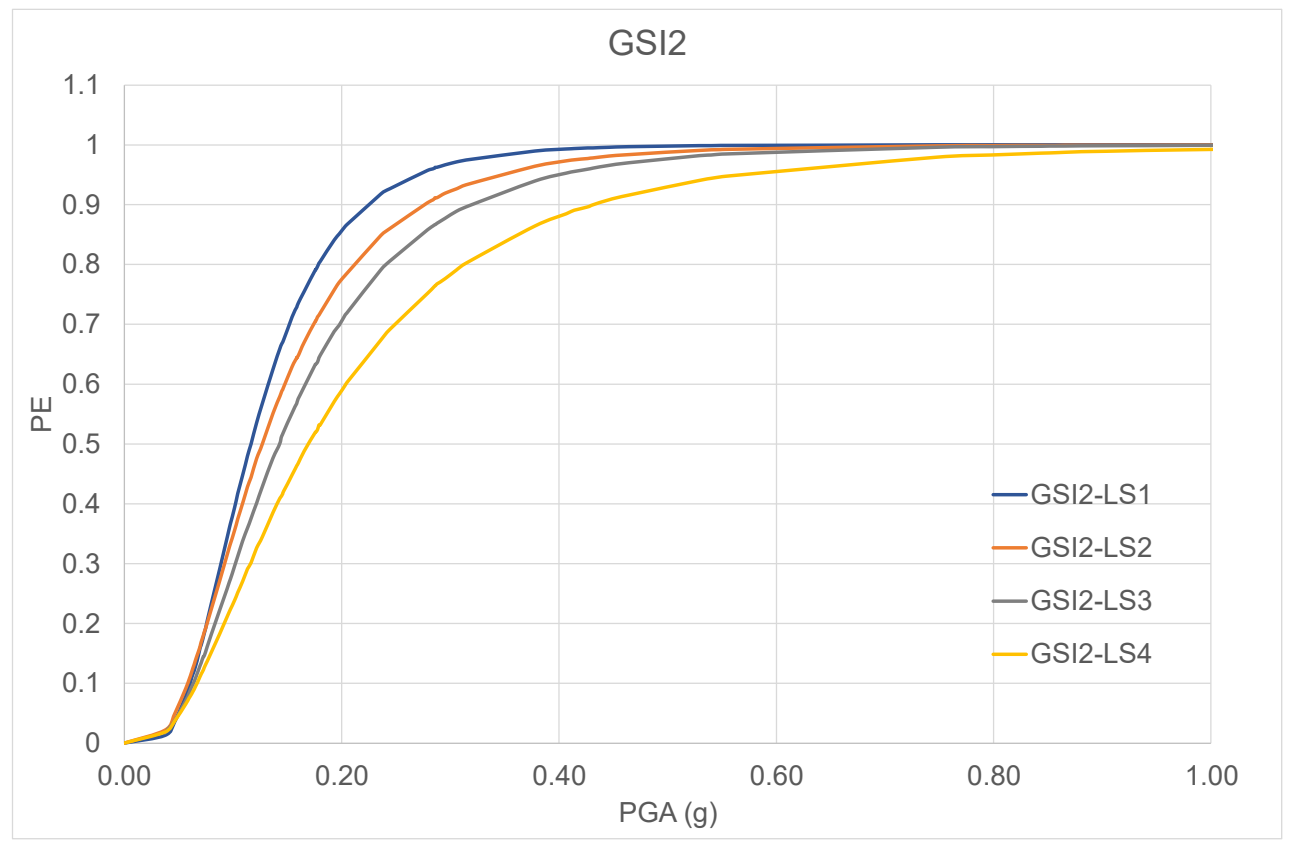

Figure 5. Fragility curve for GSI2: PGA vs. Probability of Exceedance (PE). 


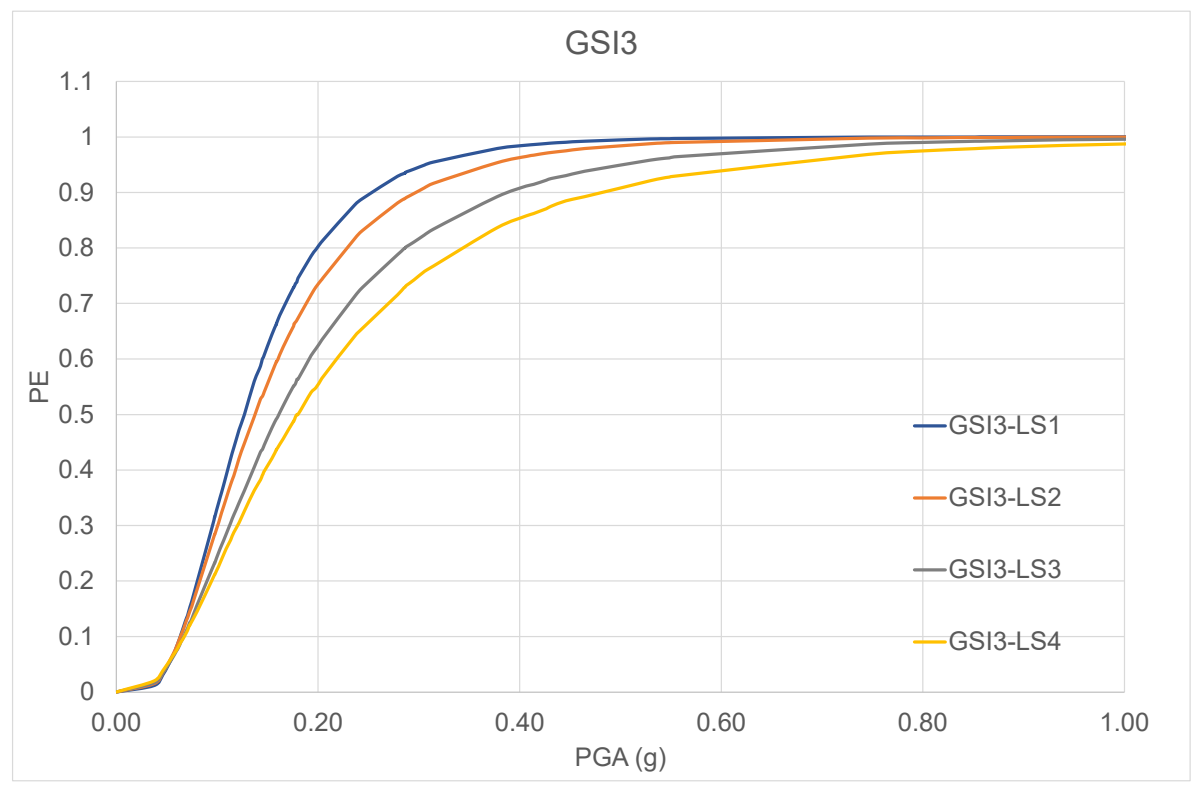

Figure 6. Fragility curve for GSI3: PGA vs. Probability of Exceedance (PE).

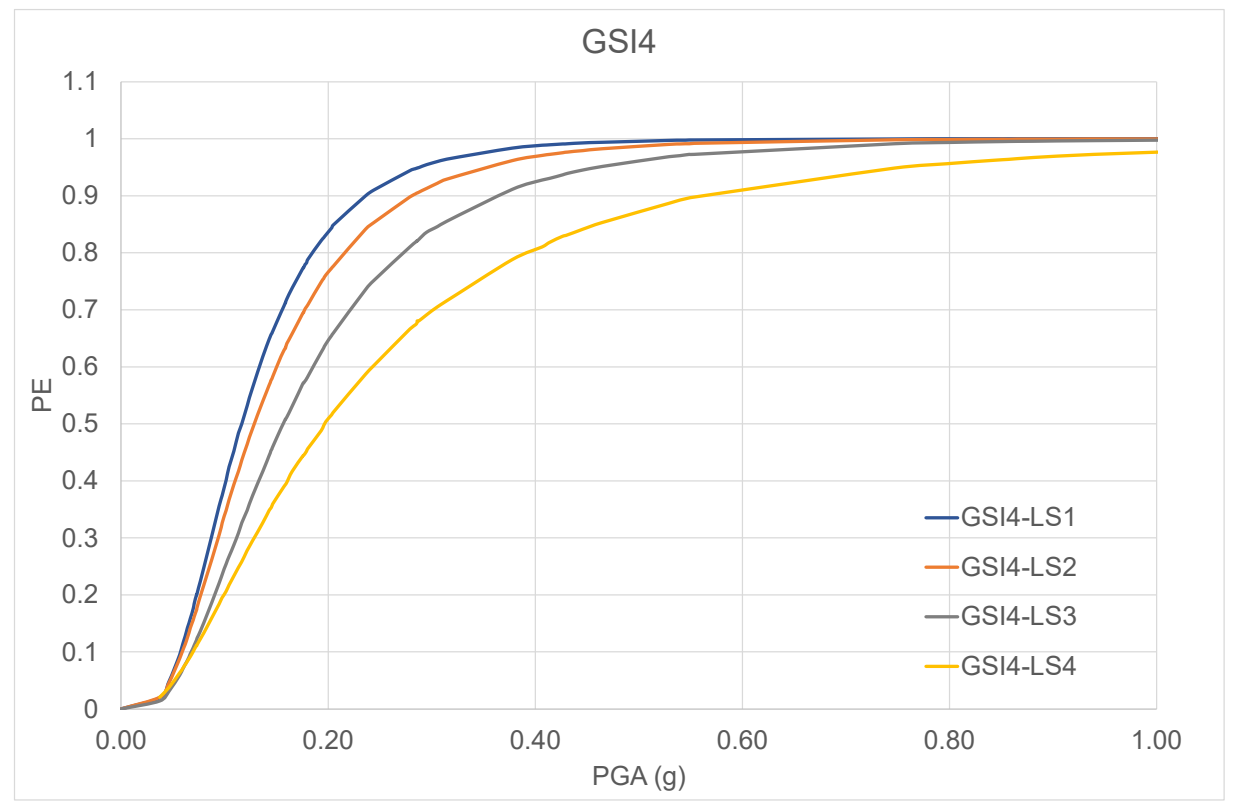

Figure 7. Fragility curve for GSI4: PGA vs. Probability of Exceedance (PE).

Figure 8 shows the comparison between the fragility curves for all the configurations for LS4 (complete damage, drift: $4 \%$ ). In particular, the probability of exceedance (PE) varies with the location of the liner demonstrating the effect of the depth in reducing the damage among the entire range of PGA and at all the damage states. The differences between the configurations increases gradually as the severity of the motion increases, as shown in Table 7 that compares the values of PE for increasing intensities: $0.20 \mathrm{~g}, 0.40 \mathrm{~g}$ and $0.60 \mathrm{~g}$. In particular, when PGA $=0.40 \mathrm{~g}, \mathrm{PE}$ are $0.900,0.885,0.858$ and 0.810 , respectively, for GSI1, GSI2, GSI3 and GSI4, demonstrating that fragility curve shift toward more fragile when the depth of the liner reduces. Therefore, it is important for design purposes to consider that the most vulnerable configuration is GSI1, where the liner is superficial. Therefore, the optimal configuration needs to be a compromise between costs (deeper liners mean higher costs) and effectiveness. 


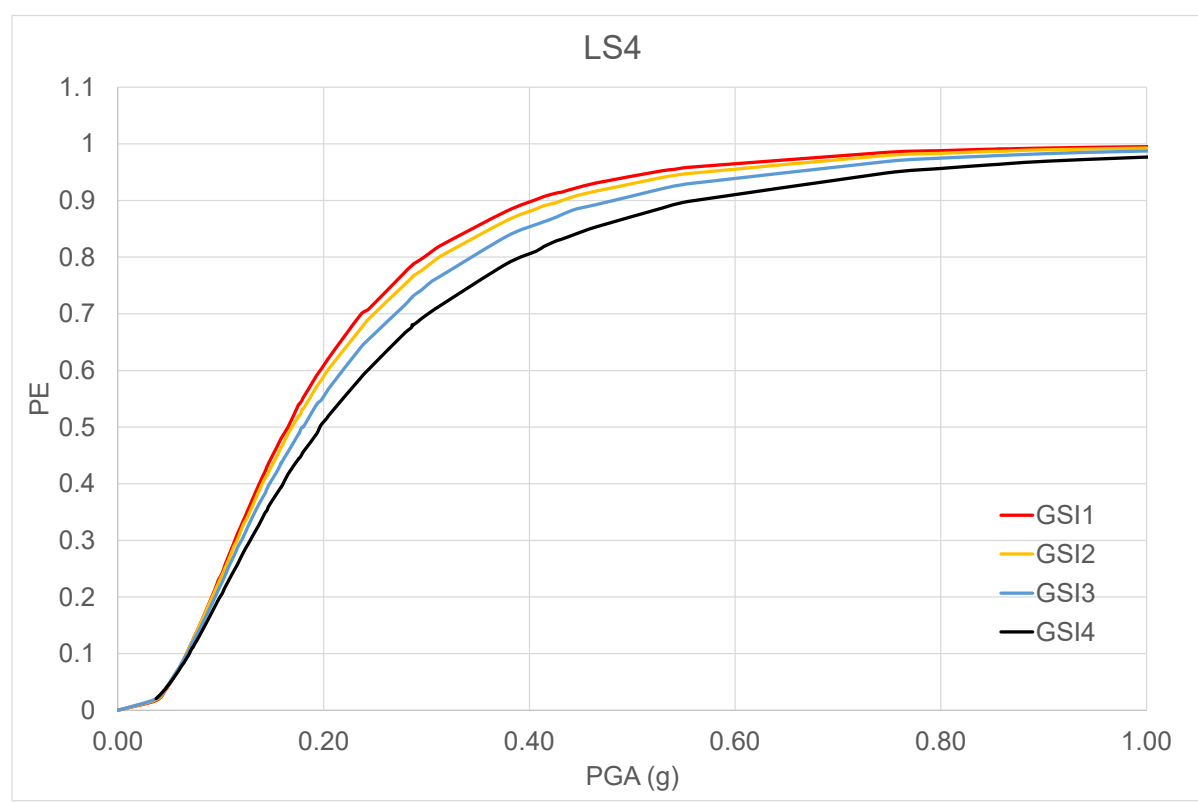

Figure 8. Comparison: fragility curve for GSI1-4, LS4 (drift: 4\%): PGA vs. Probability of Exceedance (PE).

Table 7. Comparison for LS4 for PGA $=0.20 \mathrm{~g}, 0.40 \mathrm{~g}, 0.60 \mathrm{~g}$.

\begin{tabular}{cccc}
\hline Configuration & PGA $=\mathbf{0 . 2 0} \mathbf{g}$ & PGA $=\mathbf{0 . 4 0} \mathbf{g}$ & PGA = 0.60 g \\
\hline GSI1 & 0.599 & 0.900 & 0.984 \\
GSI2 & 0.583 & 0.885 & 0.979 \\
GSI3 & 0.548 & 0.858 & 0.968 \\
GSI4 & 0.516 & 0.810 & 0.950 \\
\hline
\end{tabular}

\section{Conclusions}

3D numerical analyses have been conducted to assess the response of four GSI configurations with liners at increasing depths. The study focused on reproducing 70 input motions with several intensities in order to follow a probabilistic-based approach that may account of many uncertainties. Analytical fragility curves were developed to assess the role of liner position in reducing the damage to the structure in terms of interstory drifts. Four limit states (slight, moderate, extensive, complete) were considered and defined as $0.33 \%$, $0.58 \%, 1.56 \%$ and $4 \%$, respectively. The results allow several important considerations.

1. Developing fragility curves was necessary in order to apply a probabilistic-based approach that allows to consider the uncertainties that are connected with the problem: soil characterization, earthquakes definition, structural model and choice of the damage indicators.

2. The vulnerability of the system depends on many factors, such as the coupled behaviour of the structure and the isolation. In this regard, applying a high nonlinear 3D numerical model was fundamental to realistically represent the complex mechanisms due to SSI.

3. The role of the location of the liner to reduce the damage and thus the vulnerability of the system (soil + structure) to earthquake motions. In particular, this outcome may be potentially applied to develop code prescriptions.

4. From a design point of view, it is fundamental to consider two important aspects: costs (that increase with the depth of the liner) and GSI effectiveness that was demonstrated to depend on the position of the liner. The deeper the position of the liner is, the less vulnerable the system becomes, thanks to the role of GSI in decoupling the ground from the superstructure. 
Finally, note that these results are limited to the proposed case studies. However, they may have interesting applications for the design of GSI configurations.

Funding: No fund has been received to conduct this research.

Data Availability Statement: The data are available upon request from the authors.

Conflicts of Interest: The author declares no conflict of interest.

\section{References}

1. Forcellini, D. Assessment of Geotechnical Seismic Isolation (GSI) as a Mitigation Technique for Seismic Hazard Events. Geosciences 2020, 10, 222. [CrossRef]

2. Gatto, M.P.A.; Lentini, V.; Castelli, F.; Montrasio, L.; Grassi, D. The use of polyurethane injection as a geotechnical seismic isolation method in large-scale applications: A numerical study. Geosciences 2021, 11, 201. [CrossRef]

3. Gatto, M.P.A.; Montrasio, L.; Berardengo, M.; Vanali, M. Experimental Analysis of the Effects of a Polyurethane Foam on Geotechnical Seismic Isolation. J. Earthq. Eng. 2020. [CrossRef]

4. Gatto, M.P.A.; Montrasio, L.; Tsinaris, A.; Pitilakis, D.; Anastasiadis, A. The dynamic behaviour of polyurethane foams in geotechnical conditions. In Proceedings of the 7th International Conference on Earthquake Geotechnical Engineering, Rome, Italy, 17-20 June 2019.

5. Tsiavos, A.; Sextos, A.; Stavridis, M.; Dietz, L.; Dihoru, L.; Alexander, N.A. Large-scale experimental investigation of a low-cost PVC 'sand-wich' (PVC-s) seismic isolation for developing countries. Earthq. Spectra 2020, 36, 1886-1911. [CrossRef]

6. Azinović, V.; Kilar, D.; Koren, V. The seismic response of low-energy buildings founded on a thermal insulation layer -a parametric study. Eng. Struct. 2014, 81, 398-411. [CrossRef]

7. Banović, I.; Radnić, J.; Grgić, N. Geotechnical seismic isolation system based on sliding mechanism using stone pebble layer: Shake-table experiments. Shock Vib. 2019, 26. [CrossRef]

8. Xiong, W.; Li, Y. Seismic isolation using granulated tire-soil mixtures for less-developed regions: Experimental validation. Earthq. Eng. Struct. Dyn. 2013, 42, 2187-2193. [CrossRef]

9. Bandyopadhyay, S.; Sengupta, A.; Reddy, G.R. Natural base isolation system for earthquake protection. Curr. Sci. 2014, 107, 1037-1043.

10. Tsiavos, A.; Alexander, N.A.; Diambra, A. A sand-rubber deformable granular layer as a low-cost seismic isolation strategy in developing countries: Experimental investigation. Soil Dyn. Earthq. Eng. 2019, 125, 105731. [CrossRef]

11. Tsang, H.; Tran, D.; Hung, W.; Pitilakis, K.; Gad, E. Performance of geotechnical seismic isolation system using rubber-soil mixtures in centrifuge testing. Earthq. Eng. Struct. Dyn. 2021, 50, 1271-1289. [CrossRef]

12. Kaneko, T.; Orense, R.P.; Hyodo, M.; Yoshimoto, N. Seismic response characteristics of saturated sand deposits mixed with tire chips. J. Geotech. Geoenviron. Eng. 2013, 139, 633-643. [CrossRef]

13. Tsang, H.H.; Lo, S.H.; Xu, X.; Sheikh, M.N. Seismic isolation for low-to-medium-rise buildings using granulated rubber-soil mixtures: Numerical study. Earthq. Eng. Struct. Dyn. 2012, 41, 2009-2024. [CrossRef]

14. Brunet, S.; de la Llera, J.C.; Kausel, E. Non-linear modeling of seismic isolation systems made of recycled tire-rubber. Soil Dyn. Earthq. Eng. 2016, 85, 134-145. [CrossRef]

15. Forcellini, D. Assessment on geotechnical seismic isolation (GSI) on bridge configurations. Innov. Infrastruct. Solut. 2017, 2, 9. [CrossRef]

16. Nanda, R.P.; Dutta, S.; Khan, H.A.; Majumder, S. Seismic protection of buildings by rubber-soil mixture as foundation isolation. Int. J. Geotech. Earthq. Eng. 2018, 9, 99-109. [CrossRef]

17. Dhanya, J.S.; Boominathan, A.; Banerjee, S. Response of low-rise building with geotechnical seismic isolation system. Soil Dyn. Earthq. Eng. 2020, 136, 106187. [CrossRef]

18. Mazzoni, S.; McKenna, F.; Scott, M.H.; Fenves, G.L. Open System for Earthquake Engineering Simulation, User CommandLanguage Manual. 2009. Available online: http://opensees.berkeley.edu/OpenSees/manuals/usermanual (accessed on 7 July 2021).

19. Lu, J.; Elgamal, A.; Yang, Z. OpenSeesPL: 3D Lateral Pile-Ground Interaction, User Manual, Beta 1.0. 2011. Available online: http:/ / soilquake.net/openseespl/ (accessed on 7 July 2021).

20. Forcellini, D. Soil-structure interaction analyses of shallow-founded structures on a potential-liquefiable soil deposit. Soil Dyn. Earthq. Eng. 2020, 133, 106108. [CrossRef]

21. Forcellini, D. Analytical fragility curves of shallow-founded structures subjected to Soil Structure Interaction (SSI) effects. Soil Dyn. Earthq. Eng. 2021, 1413, 106487. [CrossRef]

22. FEMA. HAZUS-MH MR5 Technical Manual 2008; The Federal Emergency Management Agency: Washington, DC, USA, 2008. 